\title{
Detecção sorológica e molecular de Anaplasma marginale em búfalos na Ilha de Marajó, Pará ${ }^{1}$
}

\author{
Jenevaldo Barbosa da Silva ${ }^{2 *}$, Cinthia Távora de Albuquerque Lopes ${ }^{3}$, Melina Garcia \\ Saraiva de Souza ${ }^{3}$, André Felipe Bagarrão Gibson ${ }^{3}$, Wagner Marcelo de Souza \\ Vinhote $^{3}$, Adivaldo Henrique da Fonseca ${ }^{4}$, Flábio Ribeiro de Araújo ${ }^{5}$ \\ e José Diomedes Barbosa-Neto ${ }^{3}$
}

\begin{abstract}
Silva J.B., Lopes C.T.A., Souza M.G.S., Gibson A.F.B., Vinhote W.M.S., Fonseca A.H., Araújo F.R. \& Barbosa-Neto J.D. 2014. [Serological and molecular detection of Anaplasma marginale in water buffaloes on Marajó Island, State of Pará, Brazil.] Detecção sorológica e molecular de Anaplasma marginale em búfalos na Ilha de Marajó, Pará. Pesquisa Veterinária Brasileira 34(1):11-14. Departamento de Epidemiologia e Saúde Pública, Universidade Federal Rural do Rio de Janeiro, BR-465 Km 7, Seropédica, RJ 23890-000, Brazil. E-mail: jenevaldo@hotmail.com

The aim of the study was to test the molecular and serological prevalence of Anaplasma marginale in water buffaloes of the Marajó Island, State of Pará, Brazil. For serologic research were randomly selected 800 buffaloes and for molecular research 50 of these animals were randomly chosen. To quantify the serological prevalence we used the indirect enzyme linked immunosorbent assay (iELISA) with total antigen containing proteins outer surface. To quantify the prevalence molecular was used the polymerase chain reaction (PCR) involving gene amplification fragment larger surface protein 5 (MSP5). The prevalence of positive animals in iELISA was 25\% (200/800). In the PCR we detected the presence of A. marginale in $2 \%(1 / 50)$ of animals. Although only one animal was positive in PCR, we found that it was negative in ELISA. The presence of the agent, even in low prevalence, shows that buffaloes can act as an important reservoir for transmission of the pathogen to cattle in northern Brazil.
\end{abstract}

INDEX TERMS: Anaplasma marginale, anaplasmosis, buffaloes, ELISA, MSP5, PCR.

RESUMO.- 0 objetivo do estudo foi testar a prevalência sorológica e molecular de Anaplasma marginale em búfalos do municipio de Soure, Ilha de Marajó, estado do Pará, Brasil. Para a pesquisa sorologica foram selecionados randomica-

\footnotetext{
${ }^{1}$ Recebido em 10 de junho de 2013.

Aceito para publicação em 1 de outubro de 2013.

${ }^{2}$ Laboratório de Imunodiagnóstico, Departamento de Patologia Veterinária, Facudade de Ciências Agrárias e Veterinárias (FCAV), Universidade Estadual Paulista (Unesp), Via de Acesso Prof. Paulo Donato Castellane s/n, Jaboticabal, SP 14884-900, Brasil. *Autor para correspondência: jenevaldo@hotmail.com

3 Departamento de Ciência Animal, Centro Agropecuário, Universidade Federal do Pará, Rua Maximino Porpino da Silva 1000, Castanhal, PA 68740-080, Brasil. E-mail: diomedes@ufpa.br

4 Laboratório de Doenças Parasitárias, Departamento de Epidemiologia e Saúde Pública, Universidade Federal Rural de Rio de Janeiro (UFRRJ), BR-465 Km 7, Seropédica, RJ 23890-000, Brasil. E-mail: adivaldo@ufrrj.br

5 Embrapa Gado de Corte, Rodovia BR-262 Km 4, Campo Grande, MS 79002-970, Brasil. E-mail: flabio@cnpgc.embrapa.br
}

mente 800 animais e para a pesquisa molecular 50 destes animais foram aleatoriamente escolhidos. Para quantificar a prevalência sorológica utilizou-se o ensaio de imunoadsorção enzimático indireto (iELISA) com antígeno total contendo proteínas de superfície externa e para quantificar a prevalência molecular utilizou-se a reação em cadeia da polimerase (PCR), envolvendo a amplificação de fragmento gênico da proteína de superfície maior 5 (MSP5). A prevalência de animais positivos no ELISA para A. marginale foi de $25 \%(200 / 800)$. Na PCR foi detectada a presença de $A$. marginale em 2\% (1/50) dos animais. Embora apenas um animal tenha sido positivo na PCR, observou-se que o mesmo foi negativo no ELISA. A presença do agente, mesmo em baixa prevalência, mostra que os bubalinos podem funcionar como um importante reservatório desse patógeno para os rebanhos bovinos da região norte do Brasil.

TERMOS DE INDEXAÇÃO: Anaplasma marginale, anaplasmose, bubalinos, ELISA, MSP5, PCR. 


\section{INTRODUÇÃO}

O Brasil possui o maior rebanho de búfalos do ocidente e destes, aproximadamente 61\%, 457.075 búfalos, encontra-se na Ilha de Marajó, estado do Pará (IBGE 2011). Nas últimas décadas, a bubalinocultura ganhou destaque no cenário nacional, deixando de ser apenas uma alternativa para a ocupação de terras impróprias para a criação de bovinos, passando a ser uma opção economicamente rentável. Com isso, a preocupação com o manejo sanitário tem aumentado consideravelmente, pois aspectos clínicos, patológicos e epidemiológicos ainda são pouco estudados no país.

Anaplasma marginale é uma rickettsia intracelular que parasita eritrócitos bovinos e pode ser transmitido por carrapatos, moscas hematófagas e pela placenta. 0 carrapato Rhipicephalus microplus (Starke et al. 1994) e as moscas Haematobia irritans (Allingham et al. 1994) e Stomoxys calcitrans (Potgieter et al. 1981) podem efetuar o papel importante na transmissão deste patógeno para os búfalos (Mohan 1968, Costa et al. 1997, Gomes et al. 2008).

Anaplasma marginale é o mais prevalente patógeno transmitido por carrapatos no mundo, estando distribuído nos seis continentes e sendo responsável por alta morbidade e mortalidade em bovinos nas regiões temperadas, subtropicais e tropicais, incluindo o Brasil e outras regiões da América Latina (Kocan et al. 2010). Bactérias do gênero Anaplasma são patógenos intracelulares obrigatórios que podem invadir e replicar em dois ambientes distintos: células hematopoiéticas de hospedeiros mamíferos e células do intestino médio e da glândula salivar de artrópodes vetores (Ramabu et al. 2011).
Poucos estudos foram realizados com anaplasmose em bubalinos. Porém, sabe-se que, a prevalência nos búfalos e inferior ao observado nos bovinos. Rajput et al. (2005) observaram que a prevalência de $A$. marginale em búfalos é inferior a bovinos. Os autores verificaram que carrapatos que parasitavam bovinos apresentaram um maior percentual de infecção. Reddy et al. (1988) observaram que, quando intactos e não imunossuprimidos, os animais raramente apresentavam parasitemia superior a 1\%. No Brasil, Correa (2011) observou em animais naturalmente infectados uma prevalência sorológica de $43 \%$. Nesta mesma região, Souza et al. (2000) havia observado prevalência de 98\% para $A$. marginale em bovinos.

Anaplasmose bovina é responsável por perdas consideráveis na pecuária bovina brasileira. Além disso, a carência de informações sobre sanidade bubalina, motivou a realizar este estudo com o objetivo de detectar por técnicas sorológica e molecular a rickettsia Anaplasma marginale em búfalos da Ilha de Marajó, estado do Pará, Brasil.

\section{MATERIAL E MÉTODOS}

Foi realizado um estudo transversal entre 2009 e 2011. As colheitas de sangue e soro de búfalos foram realizadas no município de Soure, microrregião do Arari, Ilha de Marajó, estado do Pará, Brasil, localizada a uma latitude $00^{\circ} 43^{\prime} 00^{\prime \prime}$ sul e longitude 4831'24" oeste, com altitude de 10 metros (Fig.1).

O cálculo do tamanho mínimo da amostra foi determinado pela seguinte fórmula do Centro Panamericano de Zoonoses (1997):

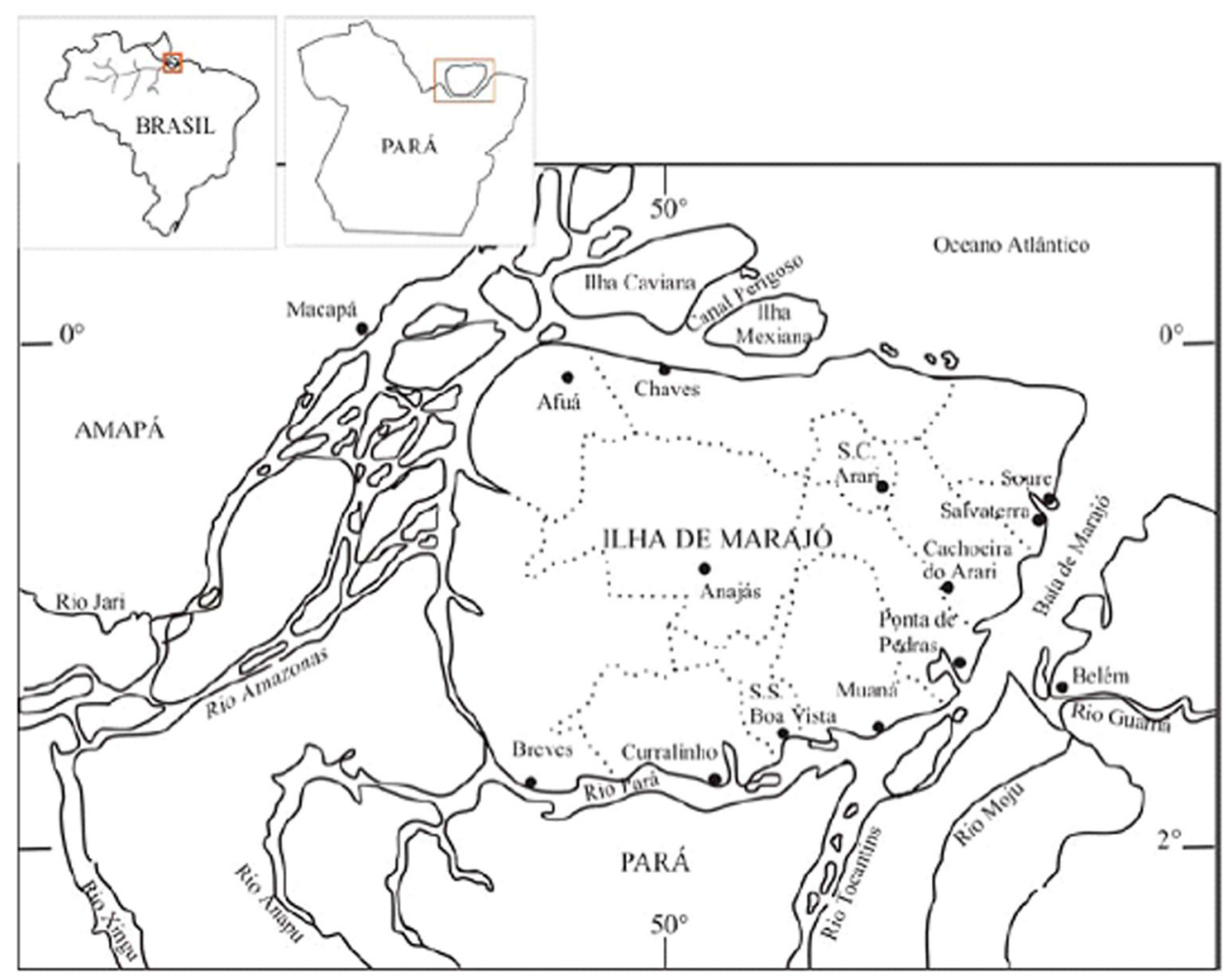

Fig.1. Mapa da Ilha de Marajó, contendo 12 municípios, limitada pelos Rios Amazonas e Pará, Baía de Marajó e Oceano Atlântico. 
$\mathrm{N}=\mathrm{p} .(100-\mathrm{p}) \mathrm{Z}^{2} /(\mathrm{d} . \mathrm{p} / 100)^{2}$

$\mathrm{N}$ = número de amostras;

$\mathrm{P}=$ prevalência esperada;

$\mathrm{Z}=$ grau de confiança;

$\mathrm{D}=$ margem de erro.

Para os valores de prevalência esperada (p) para Anaplasma marginale em búfalos, foi utilizado uma prevalência estimada de $35 \%$. A prevalência estimada foi baseada nos achados de Correa et al. (2011) em búfalos no Rio de Janeiro e Guedes-Junior et al. (2008) em bovinos no Pará. Utilizamos uma prevalência inferior ao observado nos dois trabalhos, pois como não há estudos com anaplasmose em bubalinos na Ilha do Marajó, optamos por uma margem de segurança maior. 0 intervalo de confiança foi de $95 \%$ e a margem de erro foi de 5\%. Assim, a amostra mínima esperada era de 671 animais. Porém, foi possivel selecionar 800 bubalinos. Os animais eram da raça Murrah, idade entre 1 e 3 anos, de sexo feminino e mantidos em sistema de criação extensiva.

Os títulos de anticorpos anti-A.marginale foram determinados pelo Ensaio de Imunoadsorção Enzimático indireto (iELISA), segundo Machado et al. (1997). Como controles positivos, foram utilizados soros de bubalinos com alta parasitemia (qPCR) e alto título de anticorpos (ELISA e RIFI). Como controles negativos, utilizaram-se soros de bubalinos recém-nascidos que não ingeriram colostro e negativos na PCR e ELISA/RIFI. A leitura foi realizada em leitor de ELISA, em um comprimento de onda de 405nm.

A atividade enzimática de cada soro no iELISA foi calculada mediante determinação do valor da amostra em relação ao referencial positivo (A/P). Os valores A/P foram agrupados em níveis ELISA (NE), que variaram de zero a nove. A amplitude máxima do NE zero foi determinada pela média dos valores em absorbância de soros de animais soronegativos acrescida de dois desvios padrões da média, conforme estabelecido por Machado et al. (1997). A partir deste limite, os intervalos entre os outros níveis no ELISA foram acrescidos de 35\% cada, segundo Wilson et al. (1984) para o sistema Newcastle.

0 ponto de corte do teste foi determinado segundo Frey et al. (1998). Os soros de búfalos negativos foram utilizados para definir a linha de corte do ensaio, discernindo os animais positivos e negativos com nível de confiança de 99,0\%. A fórmula matemática de Frey se baseia em um fator $t$ (distribuição t-Student), determinado pelo número de controles negativos e no nível de confiança desejado:

Linha de corte $=X+S D \times t \sqrt{1+(1 / n)}$

$X=$ média das densidades ópticas dos controles negativos;

$S D=$ desvio padrão das densidades ópticas dos controles negativos;

$t=$ valor da distribuição $t$, baseado em $n$ e no de nível de confiança desejado;

$n=$ número de controles negativos.

Para corrigir o efeito da variação da densidade óptica (DO) obtidas com a leitura de cada placa testada, o valor da linha de corte de cada uma das placas foi igualado a 100 (DO soro teste x 100/ linha de corte) e os resultados de cada soro teste foram expressos na forma de Índice de Densidade Óptica (IDO).

Posteriormente, foram selecionados aleatoriamente 6,25\% (50/800) das amostras para realização da PCR segundo Torioni De Echaide et al. (1998). Para isso o DNA das amostras foi extraído, utilizando o QIAamp DNA Blood Mini Kit (Qiagen $®$ ), para determinar se os animais estavam parasitados por A. marginale.

A frequência de animais positivos para $A$. marginale no iELISA e PCR foram comparados pelo teste de Qui-quadrado ( $\chi 2$ ) a $95 \%$ de confiança. A concordância entre a frequência de animais positivos na PCR convencional e iELISA foi avaliada utilizando o índice Kappa (Kramer; Feinstein, 1981). Os procedimentos operacionais foram feitos utilizando o software R Foundation computação estatística, versão 2.12 .2 (2011).

\section{RESULTADOS}

Os valores médios e desvios padrões da densidade óptica dos controles negativos e positivos para Anaplasma marginale foram $0.141 \pm 0.03$ e $1.10 \pm 0.10$, respectivamente. Foram considerados positivos animais que apresentaram valores de densidade optica igual ou superior a 0.270 (Nível de Elisa 3). A classificação dos soros em níveis de ELISA (NE) está representada na tabela abaixo (Quadro 1).

Quadro 1. Valores de densidade óptica das amostras em relação ao referencial positivo (A/P), níveis de ELISA (NE) e percentual de animais em cada intervalo

\begin{tabular}{ccc}
\hline $\mathrm{NE}$ & $\mathrm{A} / \mathrm{P}$ & Anaplasma marginale \\
\hline 0 & $0-0.144$ & $31.25 \%$ \\
1 & $0.145-0.195$ & $20.00 \%$ \\
2 & $0.196-0.264$ & $18.75 \%$ \\
3 & $0.265-0.357$ & $12.50 \%$ \\
4 & $0.358-0.483$ & $07.50 \%$ \\
5 & $0.484-0.653$ & $02.50 \%$ \\
6 & $0.654-0.882$ & $02.50 \%$ \\
7 & $0.883-1.192$ & $02.50 \%$ \\
8 & $1.193-1.610$ & $01.25 \%$ \\
9 & $>1.610$ & $01.25 \%$
\end{tabular}

Os resultados demonstram que mais de $50 \%$ dos animais avaliados encontram-se nos dois primeiros NE e apenas $24.87 \%$ dos búfalos apresentaram reação positiva para A. marginale. Porém, 10 animais $(1.25 \%)$ foram agrupados no NE 9, ou seja, estes possuíram taxas de anticorpos contra A. marginale superior aos controles positivos. Além disso, outros 10 animais apresentaram níveis de anticorpos similares aos controles positivos. Esses resultados demonstraram que estes animais provavelmente foram acometidos pelo agente pouco tempo antes da avaliação.

A PCR para A. marginale realizada com as 50 amostras de DNA bubalino resultou positiva apenas para 1 animal (2.0\%). 0 único animal positivo para DNA de A. marginale na PCR mostrou-se negativo no teste sorológico ELISA.

\section{DISCUSSÃO}

Embora já existam alguns trabalhos que relatem a prevalência de Babesia sp. em búfalos (Liu et al. 1997, Terkawi et al. 2011), estes estudos ainda são raros quando se refere a Anaplasma marginale. No Brasil, Corrêa (2011) observou que a soroprevalência de $A$. marginale em bubalinos é bem distinta dos valores observados para bovinos. Neste estudo, Corrêa (2011) observou uma variação de 31.1 a 100\% de soropositividade para A marginale. Em contra partida, a maioria dos estudos realizados em bovinos no Brasil relatam valores sempre próximos a 100\% (Vidotto et al. 1998, Madruga et al. 2000, Souza et al. 2000, Barros et al. 2005).

Bubalinos tem mostrado ser pouco sensível a anaplasmose clínica, sendo mais importante seu papel como reser- 
vatório da doença. Porém, bubalinos experimentalmente infectados, embora com parasitemia inferior a $1 \%$, podem apresentar todos os sinais clínicos da anaplasmose bovina (Srivastava \& Ahluwalia 1974). No presente estudo não foi observado sinais clínicos de anaplasmose em nenhum animal. Assim, embora os bubalinos possam apresentar elevados títulos de anticorpos, a ausência de sinais clínicos colocam estes animais como importantes reservatórios do A. marginale (Sharma 1987). No Brasil, apenas um estudo relatou a presença de sinais clínicos da anaplasmose em búfalos (Franzolin et al. 1989).

Apenas um animal apresentou-se positivo para A. marginale na PCR. Este resultado comprova a infecção de bubalinos por esta rickettsia em búfalos da Ilha de Marajó, porém apresentando baixa frequência e/ou baixo nível de parasitemia para ser detectável pelo teste utilizado. Sharma (1987) afirma que em bubalinos a parasitemia por $A$. marginale é rara e geralmente abaixo de $1 \%$.

Os resultados da PCR corroboram Corrêa (2011), que ao trabalhar com bubalinos do estado do Rio de Janeiro observou que apenas 16 animais (5.4\%) foram positivos na PCR para A. marginale. No Brasil apenas o estudo de Corrêa (2011) relata o uso de técnicas moleculares no diagnóstico de anaplasmose bubalina.

\section{CONCLUSÕES}

Esse foi o primeiro estudo epidemiológico envolvendo diagnóstico sorológico e molecular da anaplasmose bubalina na Ilha de Marajó.

A presença do agente, mesmo em baixa prevalência, mostra que os bubalinos podem funcionar como um importante reservatório desse patógeno para os rebanhos bovinos da região norte do Brasil.

Agradecimentos.- Ao Conselho Nacional de Desenvolvimento Científico e Tecnológico (CNPq) pelo apoio financeiro. Á professora Rosangela Zacarias Machado (FCAV/Unesp) por ceder o antígeno utilizado.

\section{REFERÊNCIAS}

Allingham P.G., Leatch G. \& Kemp D.H. 1994. An attempt to transmit Anaplasma marginale by buffalo flies (Haematobia irritans exigua). Aust. Vet. J. 71:122-123.

Barros S.L., Madruga C.R., Araújo F.R., Menk C.F., Almeida M.A.O., Melo E.P.S. \& Kessler R.H. 2005. Serological survey of Babesia bovis, Babesia bigemina, and Anaplasma marginale antibodies in cattle from the semiarid region of the state of Bahia, Brazil, by enzyme-linked immunosorbent assays. Mem. Inst, Oswaldo Cruz 100:613-617.

Corrêa F.N. 20011. Estudo epidemiológico de Borrelia burgdorferi, Babesia bovis, Babesia bigemina e Anaplasma marginale em búfalos (Bubalus bubalis) do Estado do Rio de Janeiro. Tese de Doutorado, Universidade Federal Rural do Rio de Janeiro, Seropédica, Rio de Janeiro. 99p.

Costa C.L. Kohayagawa A., Dell'Porto A. \& Bomfim S.R.M. 1997. Determinação dos níveis de anticorpos anti-Babesia spp. em bezerros bubalinos (Bubalus bubalis), desde o nascimento até um ano de idade. Revta Bras. Parasitol. Vet. 6:117-121.

Franzolin Neto R., Dell'Porto A. \& Ruiz R.L. 1989. Anaplasmosis and babesiosis: a clinical case in buffalo (Bubalus bubalis) calf in Brazil. Buffalo Bull. 8:54-68.

Frey A., Canzio J.D. \& Zurakowski D. 1998. A statistically defined endpoint titer determination method for immunoassays. J. Immunol. Methods 221:35-41.
Gomes R.A., Machado R.Z., Starke-Buzetti W.A. \& Bonesso M.A. 2008. Resposta imune-humoral de búfalos (Bubalus bubalis) contra Anaplasma marginale. Revta Bras. Parasitol. Vet. 17:73-80.

Guedes-Júnior D.S., Araújo F.R., Silva F.J.M., Rangel C.P., Barbosa-Neto J.D. \& Fonseca A.H. 2008. Frequency of antibodies to Babesia bigemina, B. bovis, Anaplasma marginale, Trypanosoma vivax and Borrelia burdgorferi in cattle from the northeastern region of the state of Pará, Brazil. Revta Bras. Parasitol. Vet. 17:105-109.

Kocan K.M., De La Fuente J.C., Blouin E.F., Coetzee J.F. \& Ewing S.A. 2010. The natural history of Anaplasma marginale. Vet. Parasitol. 167:95107.

Kramer M.S. \& Feinstein A.R. 1981. Clinical biostatistics. LIV. The biostatistics of concordance. Clin. Pharmacol. Ther. 29:111-123.

Liu Z., Zhao J., Ma L. \& Yao B. 1997. Studies on buffalo babesiosis in Hubei Province, China. Trop. Anim. Health Prod. 29:33-36.

Machado R.Z., Montassier H.J., Pinto A.A., Lemos E.G., Machado M.R.F., Valadão I.F.F., Barci L.G. \& Malheiros E.B. 1997. An enzyme-linked immunosorbent assay (ELISA) for the detection on antibodies against Babesia bovis in cattle. Vet. Parasitol. 71:17-26.

Madruga C.R., Marques A.P.C., Leal C.R.B., Carvalho C.M.E., Araújo F.R. \& Kessler R.H. 2000. Evaluation of enzyme-linked immunosorbent assay to detect antibodies against Anaplasma marginale. Pesq. Vet. Bras. 20:109-112.

Mohan R.N. 1968. Diseases and Parasites of Buffaloes. III. Parasitic and miscellaneous diseases. Vet. Bulletin 38:735-756.

Potgieter F.T., Sutherland B. \& Biggs H.C. 1981. Attempt to transmit Anaplasma marginale with Hippobosca ruptipes and Stomoxys calcitrans. Onderstepoort J. Vet. Res. 48:119-122.

Rajput Z.I., Hu S., Arijo A.G., Habib M. \& Khalid M. 2005. Comparative study of Anaplasma parasites in tick carrying buffaloes and cattle. J. Zhejiang Univ. Sci. 6:1057-1062.

Ramabu S.S., Schneider D.A., Brayton K.A., Ueti M.W., Graça T., Futse J.E., Noh S.M., Baszler T.V. \& Palmer G.H. 2011. Expression of Anaplasma marginale ankyrin repeat-containing proteins during infection of the mammalian host and tick vector. Infect. Immun. 79:2847-2855.

Reddy G.R., More T., Sharma S.P. \& Singh L.N. 1988. The oxidant defense system in water-buffaloes (Bubalus bubalis) experimentally infected with Anaplasma marginale. Vet. Parasitol. 27:245-249.

Sharma S.P. 1987. Characterization of Anaplasma marginale infection in buffaloes. Indian J. Anim. Sci. 57:76-78.

Souza J.C.P., Soares C.O., Massard C.L., Scofield A. \& Fonseca A.H. 2000. Soroprevalência de Anaplasma marginale em bovinos na mesorregião Norte Fluminense. Pesq. Vet. Bras. 20:97-101.

Srivastava R. \& Ahluwalia S.S. 1974. A clinical case of anaplasmosis in buffalo. Indian Vet. J. 51:371-374.

Starke W.A., Evangelista F.M.M. \& Zocoller M.C. 1994. Comparative study of the natural infection by Boophilus microplus tick between buffalo and cattle. Annals World Buffalo Congress, São Paulo, p.102.

Terkawi M.A., Huyen N.X., Shinuo C., Inpankaew T., Maklon K., Aboulaila M., Ueno A., Goo Y.K., Yokoyama N., Jittapalapong S., Xuan X. \& Igarashi I. 2011. Molecular and serological prevalence of Babesia bovis and Babesia bigemina in water buffaloes in the northeast region of Thailand. Vet. Parasitol. 178:201-207.

Torioni De Echaide S., Knowles D.P., Mcguire T.C., Palmer G.H., Suarez C.E. \& McElwain T.F. 1998. Detection of cattle naturally infected with Anaplasma marginale in a region of endemicity by nested PCR and competitive enzyme-linked immunosorbent assay using recombinant major surface protein 5. J. Clin. Microbiol. 36:777-782.

Vidotto M.C., Vidotto O., Andrade G.M., Palmer G., McElwain T. \& Knowles D.P. 1998. Seroprevalence of Anaplasma marginale in cattle in Paraná State, Brazil, by MSP-5 competitive ELISA. Ann. N.Y. Acad. Sci. 849:424426.

Wilson R.A., Perrota Jr C., Frey B. \& Eckroade R.J. 1984. An enzyme-linked immunosorbent assay that measures protective antibody levels to Newcastle disease virus in chickens. Avian Dis. 28:1079-1085. 